\title{
Computing Measurements of Femoral Neck Shaft Angle in Children and Adolescents from Nile Delta
}

\author{
Ahmed Zaghloul*, Elalfy M Mohamed, Medhat Tawfik Maaty, Gamal El-Adl El-Saied and Akram Hammad \\ Department of Orthopaedic Surgery, Faculty of Medicine, Mansoura University, Egypt
}

Submission: July 27, 2020; Published: September 28, 2020

*Corresponding author: Ahmed Zaghloul, Department of Orthopaedic Surgery, Faculty of Medicine, Mansoura University, Egypt

Abstract

Background: Despite ongoing anthropological and orthopaedic interest in the ranges and patterns of variation of the femoral neck shaft angle (NSA) under varying normal and abnormal conditions, there has been little consideration of normal ranges of variation of this trait in Egyptian populations.

Purpose: This study was designed to evaluate the normal values of femoral NSA in Egyptian children and adolescents and factors which may affect this angle.

Study type: A Cross Sectional Descriptive study.

Methods: This study included 200 hips in 100 normal children and adolescents from the attendants of Orthopaedic Outpatient Clinics, in our institution. All individuals were subjected to a comprehensive orthopaedic examination to exclude those with orthopaedic problems affecting lower limbs or are likely to affect lower limbs e.g. spine and pelvis. Computed Tomography (CT) was used in measurement of femoral NSA through an Antero-Posterior Scanogram of pelvis and thigh.

Results: This study included 49 males and 51 females with mean age of $9.78 \pm 3.06$ years. The mean body weight of the subjects was $34.78 \pm 14.16 \mathrm{Kg}$, the mean height $132.09 \pm 17.59 \mathrm{~cm}$ and the mean Body Mass index (BMI) was $19.14 \pm 3.92$. The NSA ranged from $116^{\circ}$ to $148^{\circ}$ with mean angle of $133.23^{\circ} \pm 5.30$ regardless the side. The means of NSA of the right and left sides were nearly equal with significant differences were found when right and left sides were compared in every subject. There were negative correlations between age, weight, height, BMI and NSA with no significant sex-specific differences reported.

Conclusion: There are many factors which may influence NSA size, for example: studied population, age, weight, height, side, and BMI.

Keywords: Femoral; Neck Shaft Angle; Children; Adolescents; Egyptian

\section{Overview}

According to the literature, there has been little consideration of normal ranges and variations of this trait in Egyptian populations, especially in Children and adolescents. This study may help to determine normal values of femoral NSA in Egyptian children and adolescents and factors which may affect this angle e.g. age, sex, side, weight, height, and BMI. Hence, we can make the best benefit of radiological studies and reach maximum efficacy in dealing with hip disorders which may correlate with variations of femoral NSA in this age group.

\section{Introduction}

The proper action of hip joint depends on the congruence of articular surfaces of the head of the femur and the acetabulum [1].
So, morphology of the proximal femur, especially, the relationships among the head, neck, and proximal shaft, has been a subject of interest and debate in orthopaedic literature dating back to at least the middle of $19^{\text {th }}$ century. As an area susceptible to numerous paediatric and adult disorders, many of which may correlate with variations in this morphology or whose treatment might benefit from a detailed understanding of this area's anatomy [2].

The femoral head comprises $2 / 3$ of a sphere. It is attached to the femoral metaphysis via the neck [3]. The femoral neck is well developed in humans, with global orientation slanting upwards and forwards [4]. The direction of the femoral neck is characterized by two factors: inclination and anteversion [5]. The femoral neck inclination or femoral neck-shaft angle (NSA) is the 
angle between the longitudinal axes of the femoral neck and the shaft and it is also called Caput- Collum - Diaphyseal angle (CCD angle) [6]. In normal hips NSA should cause the longitudinal axes of the femoral necks to cross at the point of body weight [1]. Also, the importance of this feature is that the femoral shaft is laterally displaced from the pelvis, thus facilitating for joint motion [3].

Several factors are quoted which influence NSA size in postnatal life: epiphyseal cartilage activity, perfusion of femoral epiphysis, muscle action, hormones, static factors, body weight and finally disease. The most spectacular is the influence of age during human growth from childhood to adulthood the NSA decreases significantly. This is a result of changes in body proportions followed by adaptation of the hip joint to vertical posture and gait in changed conditions [1]. This angle normally measures approximately $150^{\circ}$ in new-borns and $126^{\circ}$ in adults (Coxa Norma) [6]. Any deviation appearing during development which exceeds the normal values of the NSA may cause a number of disturbances [1], which may be associated with problems in the loading of the hip joint, that may result in non-economic gait and premature wear of the joint [4]. An abnormally small angle is known as Coxa Vara and an abnormally large angle as Coxa Valga [6].

The clinical importance of neck shaft angle of femur lies in the diagnosis, treatment, and follow-up of fractures of the femoral neck, trochanteric fractures, slipped upper femoral epiphysis, developmental dysplasia of the hip and neuromuscular disorders of the lower extremity. On the other hand, the effectiveness of management of such disturbances is often assessed by radiological studies. But the value of radiological studies has been limited because of lack of available data to establish the limits of normal measurements of this angle. From all the above, the need to know the normal measurements of the femoral NSA becomes very important to make the best benefit of radiological studies and reach maximum efficacy in dealing with those disturbances. This study is going to measure femoral NSA and to detect factors that may affect this angle as age, sex, body weight, height, and body mass index (BMI) in Egyptian children and adolescents from Nile Delta.

\section{Subjects and Methods}

\section{Study design}

A Cross Sectional Descriptive study included 200 hips in 100 normal children and adolescents from the attendants of Orthopaedic Outpatient Clinics in our institution.

\section{Sampling}

Subjects were selected to represent boys and girls in the age group between 5 years and 15 years, till fulfillment of the needed sample.

\section{Study population}

\section{A. Inclusion criteria}

Children and adolescents with orthopaedic problems not affecting the lower limbs were included.

\section{B. Exclusion criteria}

Children and adolescents with orthopaedic problems affecting lower limbs or are likely to affect lower limbs e.g. spine or pelvis, were excluded.

\section{Ethical Consideration}

The ethical committee in our institution has accepted the performance of this study. Parents' consent was mandatory for inclusion of every child or adolescent in the study after detailed explanation of the procedure and its aim and drawbacks.

\section{Subject Communication and Preparation}

Demographic data regarding name, age, sex, weight, and height were collected with complete explanation of the procedure to alleviate fears and ensure a successful procedure.

\section{Procedure}

Computed Tomography (CT) was used in determination and measurement of femoral neck shaft angle through an AnteroPosterior Scanogram of pelvis and thigh.

\section{A. Subject position}

Supine, feet-first position with his or her arms placed at sides or across upper chest. Then, align mid sagittal plane of the subject to center line of CT table (couch) (Figure 1).

\section{B. Part position}

Ensure that the pelvis is not rotated; distance from table top to each ASIS should be equal. Then, separate, and internally rotate the entire leg $15 \mathrm{o}$ to $20 \mathrm{o}$ to compensate for femoral neck anteversion and in situ external rotation of the subject (Figure 2).

\section{Radiation dose}

As for all imaging procedures, adherence to the ALARA principle was required to reduce dose to subjects and personnel.

\section{Shielding}

Anyone who must remain in the CT exam room during the procedure wearied protective lead apparel. Subject led shielding of radiosensitive organs obscure pelvis anatomy and was not used.

\section{Measurement of Neck-shaft Angle}

The NSA is the angle formed by the intersection of the femoral neck and shaft axes (Figure 3). 


\section{Orthopedics and Rheumatology Open Access Journal (OROAJ)}

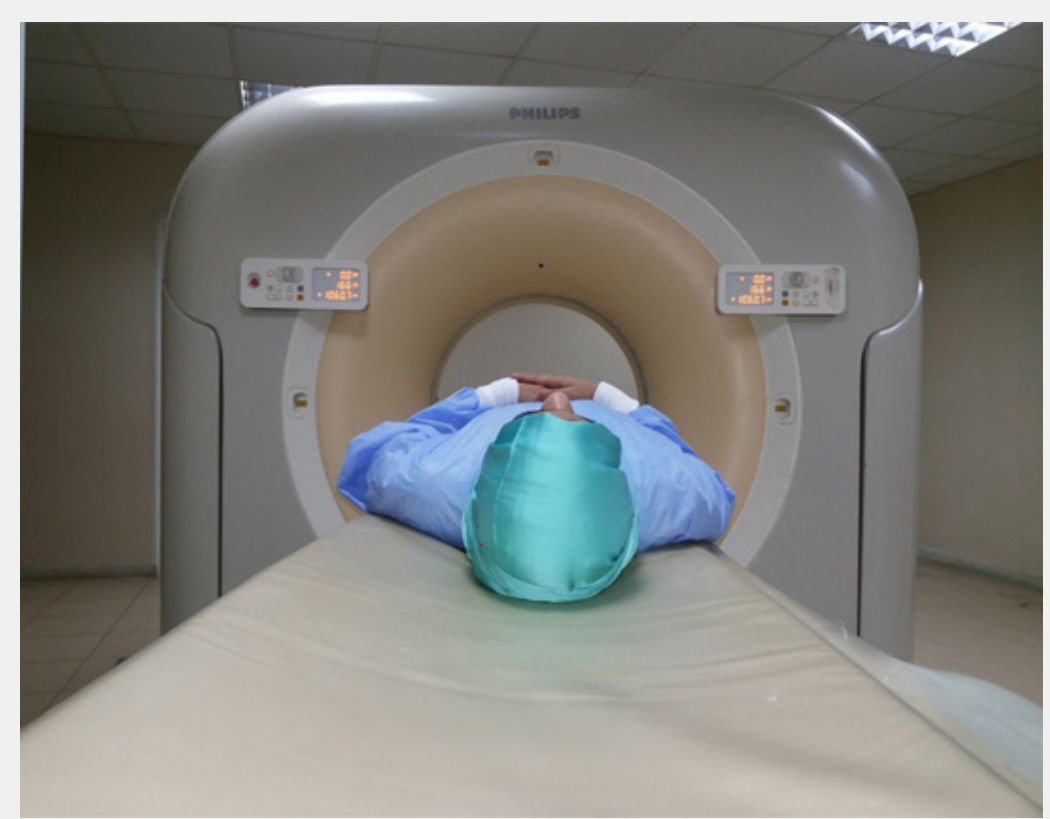

Figure 1: Subject position during imaging procedure.

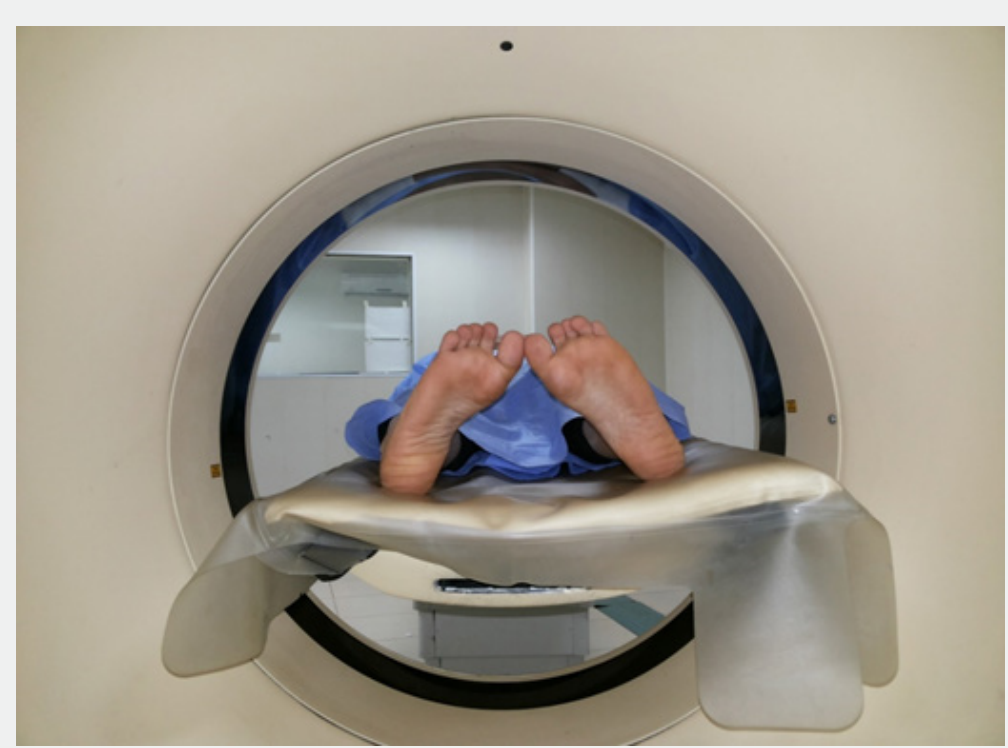

Figure 2: Part Position during imaging procedure.

\section{A. Computing the shaft Axis}

Horizontal lines in three sequential points $1 \mathrm{Cm}$ apart at the isthmus were drawn from one side of the shaft to the opposite side, and then the mid points of these lines were connected to from the shaft axis.

\section{B. Computing the Neck Axis}

The axis of the neck was drawn from the center of the head of the femur towards midpoint of the base of the neck.

\section{Statistical Analysis}

Data were analysed by SPSS software version 24. Qualitative data were expressed as number and percentage within group. Quantitative data were tested for normality using Kolmogorov Smirnov test and they were expressed as mean + standard deviation or median and range. Comparison between the quantitative data of three study groups was carried out by oneway ANOVA test. Qualitative data were compared between the three groups using Chi square test. P value $<0.05$ was considered significant in all used tests. 


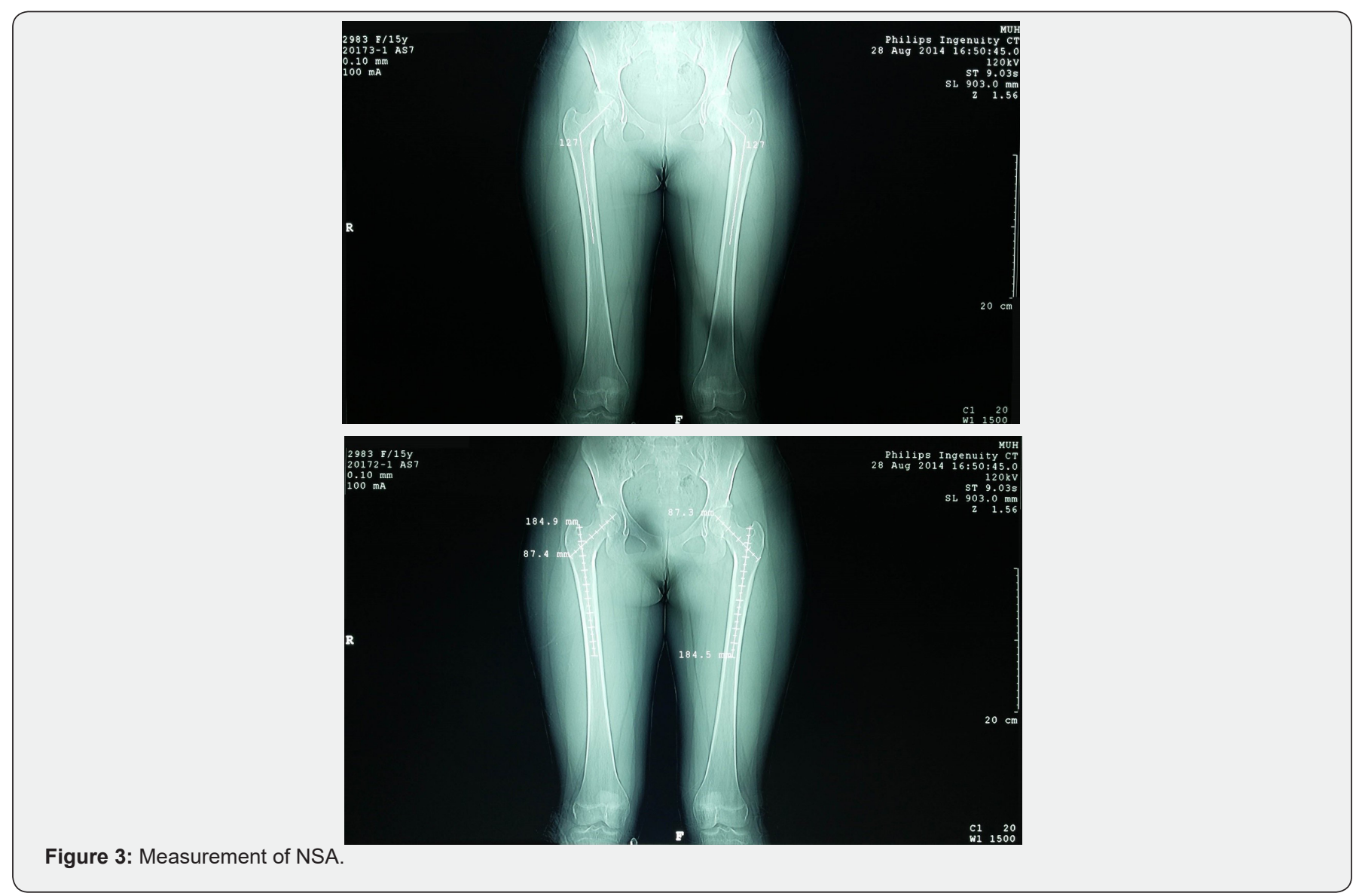

Results

\section{A. Demographic Data}

The age of the subjects included in this study ranged from 5 to 15 years old, with mean age of $9.78 \pm 3.06$ years; 49 were males $(49.0 \%)$ and 51 were females $(51.0 \%)$. The body weight of the involved individuals ranged from 17 to $79 \mathrm{Kg}$, with a mean of $34.78 \pm 14.16 \mathrm{Kg}$. The height varied from 93 to $171.5 \mathrm{~cm}$ with mean height of $132.09 \pm 17.59 \mathrm{~cm}$. The Body Mass index (BMI) was 12.5 to 35.1 with mean BMI of $19.14 \pm 3.92$.

\section{B. Neck Shaft Angle}

The neck shaft angle in the obtained sample ranged from $116^{\circ}$ to $148^{\circ}$ with mean angle of $133.23^{\circ} \pm 5.30$ regardless the side, and from $116^{\circ}$ to $148^{\circ}$ with mean angle of $133.04^{\circ} \pm 5.36$ at right side, while it was $116^{\circ}$ to $146^{\circ}$ with mean angle of $133.42^{\circ} \pm 5.27$ at left side (Table 1).

Table 1: Neck shaft angle among study population.

\begin{tabular}{|c|c|c|c|}
\hline Angle & Mean \pm SD. & Median & Min. - Max. \\
\hline $\begin{array}{c}\text { Total } \\
(\mathrm{n}=200)\end{array}$ & $133.23 \pm 5.30$ & 133 & $116-148$ \\
\hline $\begin{array}{c}\text { Right Side } \\
(\mathrm{n}=100)\end{array}$ & $133.04 \pm 5.36$ & 133 & $116-148$ \\
\hline $\begin{array}{c}\text { Left Side } \\
(\mathrm{n}=100)\end{array}$ & $133.42 \pm 5.27$ & 133 & $116-146$ \\
\hline
\end{tabular}

\section{Relation between side and NSA}

The means of neck shaft angle of the right and left sides were nearly equal. Although, significant differences were found when right and left sides were compared in every subject (using Paired t-test) reaching $1.08^{\circ} \pm 1.05$ and ranging from $0.5^{\circ}$ to $4^{\circ}$ (Table 2).

\section{Relation between age and NSA}

It was found that there was a statistically significant decrease in NSA with increasing age (Table 3).

\section{E. Relation between sex and NSA}

The difference in the NSA between males and females was found to be statistically insignificant (Table 4).

\section{F. Relation between weight and NSA}

The difference in NSA was inversely related to change in weight and was found to be statistically significant. The angle decreased with increasing weight (Table 5). 


\section{Orthopedics and Rheumatology Open Access Journal (OROAJ)}

Table 2: Relation between side and NSA.

\begin{tabular}{|c|c|c|c|c|c|}
\hline $\begin{array}{c}\text { Angle } \\
(\mathrm{n}=200)\end{array}$ & $\begin{array}{l}\text { Right Side } \\
(\mathrm{n}=100)\end{array}$ & $\begin{array}{c}\text { Left Side } \\
(\mathrm{n}=100)\end{array}$ & $\begin{array}{c}\text { Difference } \\
\text { Between sides }\end{array}$ & $\begin{array}{c}\text { Paired } \\
\text { t-test }\end{array}$ & p-value \\
\hline Mean \pm SD & $133.04 \pm 5.36$ & $133.42 \pm 5.27$ & $1.08 \pm 1.05$ & \multirow{3}{*}{2.625} & \multirow{3}{*}{$0.01 *$} \\
\hline Min. - Max. & $116-148$ & $116-146$ & $0-4$ & & \\
\hline Median & 133 & 133 & 1.00 & & \\
\hline
\end{tabular}

Table 3: Relation between age and NSA.

\begin{tabular}{|c|c|c|c|c|c|}
\hline \multirow{2}{*}{$\begin{array}{c}\text { Angle } \\
(\mathrm{n}=200)\end{array}$} & \multicolumn{3}{|c|}{ Age } & \multirow[b]{2}{*}{$\begin{array}{c}\text { p-value } \\
\text { (F) }\end{array}$} & \multirow[b]{2}{*}{$\begin{array}{l}p \text {-value } \\
\text { (r) }\end{array}$} \\
\hline & $\begin{array}{c}<8 y \\
(n=56)\end{array}$ & $\begin{array}{l}8-<12 y \\
(n=74)\end{array}$ & $\begin{array}{c}\geq \mathbf{1 2 y} \\
(\mathrm{n}=70)\end{array}$ & & \\
\hline Mean \pm SD. & $134.16 \pm 6.01$ & $133.69 \pm 4.26$ & $132.01 \pm 5.53$ & \multirow{3}{*}{$\begin{array}{l}0.049^{*} \\
(3.065)\end{array}$} & \multirow{3}{*}{$\begin{array}{l}0.008^{*} \\
(-.188)\end{array}$} \\
\hline Min. - Max. & $120-145$ & $126-148$ & $116-143$ & & \\
\hline Median & 134 & 134 & 132 & & \\
\hline
\end{tabular}

Table 4: Relation between sex and NSA.

\begin{tabular}{|c|c|c|c|}
\hline \multirow{2}{*}{$\begin{array}{c}\text { Angle } \\
(\mathrm{n}=200)\end{array}$} & $\begin{array}{c}\text { Sex } \\
(\mathrm{n}=98)\end{array}$ & $\begin{array}{c}\text { Female } \\
(\mathrm{n}=102)\end{array}$ \\
\cline { 2 - 4 } & $133.39 \pm 6.17$ & $133.08 \pm 4.32$ \\
(t-test) \\
\hline Mean \pm SD. & $116-148$ & $126-145$ \\
$(0.405)$ & 133 \\
\hline
\end{tabular}

Table 5: Relation between weight and NSA.

\begin{tabular}{|c|c|c|c|c|c|}
\hline \multirow{2}{*}{$\begin{array}{c}\text { Angle } \\
(n=200)\end{array}$} & \multicolumn{3}{|c|}{ Weight } & \multirow{2}{*}{$\begin{array}{c}\text { p-value } \\
\text { (F) }\end{array}$} & \multirow[b]{2}{*}{$\begin{array}{c}\text { p-value } \\
\text { (r) }\end{array}$} \\
\hline & $\begin{array}{l}<30 \mathbf{~ K g} \\
(n=94)\end{array}$ & $\begin{array}{c}30-<40 \mathrm{Kg} \\
(\mathrm{n}=46)\end{array}$ & $\begin{array}{l}\geq 40 \mathrm{Kg} \\
(n=60)\end{array}$ & & \\
\hline Mean \pm SD. & $134.09 \pm 5.03$ & $133.19 \pm 5.11$ & $131.91 \pm 5.66$ & \multirow{3}{*}{$\begin{array}{c}0.043^{*} \\
(3.187)\end{array}$} & \multirow{3}{*}{$\begin{array}{c}0.002^{*} \\
(-0.222)\end{array}$} \\
\hline Min. - Max. & $120-145$ & $122-143$ & $116-148$ & & \\
\hline Median & 134 & 132.75 & 132 & & \\
\hline
\end{tabular}

\section{G. Relation between height and NSA}

There was a statistically insignificant decrease in NSA with increasing height (Table 6).

\section{H. Relation between Body Mass Index (BMI) and NSA}

The difference in NSA was inversely related to change in BMI and was found to be statistically highly significant. The angle decreased with increasing BMI (Table 7).

\section{Discussion}

There has been ongoing interest in degrees and patterns of variation of the medial inclination of the femoral head and neck relative to its diaphysis at least since $[7,8]$, with the extreme vertical and horizontal positions characterized as coxa valga and coxa vara. This orientation is most effectively evaluated through its quantification by the femoral NSA (collodiaphyseal, cervicodiaphyseal angle, or angle of inclination) [9]. Despite ongoing anthropological [10-12] and especially orthopaedic [1322] interest in the ranges and patterns of variation of the femoral NSA under varying normal and abnormal conditions, there has been little consideration of normal ranges and variations of this trait in Egyptian populations.

Previous studies investigating the morphometry of the hip and proximal femur varied in the technique used and populations studied. Most authors agree that there is considerable individual variation and wide standard deviation in NSA. Some studies have used measurements obtained directly from the dry bones [16,23-26] or radiographic examination of dry femurs $[2,27$, $28,29]$, whereas others have used radiological studies of subjects e.g. radiographs [30-35], computed tomography (CT) [36] and 
DXA-based measurements [37-39]. In this work we measured NSA using CT Scanogram in Egyptian children \& adolescents in the age group between 5 and 15 years old. As, several studies
$[7,8,11,18,21]$ have shown that the NSA is very stable from midadolescence through most of adulthood.

Table 6: Relation between height and NSA.

\begin{tabular}{|c|c|c|c|c|c|}
\hline \multirow{2}{*}{$\begin{array}{c}\text { Angle } \\
(n=200)\end{array}$} & \multicolumn{3}{|c|}{ Height } & \multirow{2}{*}{$\begin{array}{l}\text { p-value } \\
\text { (F) }\end{array}$} & \multirow{2}{*}{$\begin{array}{c}p \text {-value } \\
\text { (r) }\end{array}$} \\
\hline & $\begin{array}{l}<120 \mathrm{~cm} \\
(\mathrm{n}=60)\end{array}$ & $\begin{array}{c}120-<140 \mathrm{~cm} \\
(\mathrm{n}=78)\end{array}$ & $\begin{array}{l}\geq 140 \mathrm{~cm} \\
(\mathrm{n}=62)\end{array}$ & & \\
\hline Mean \pm SD. & $133.82 \pm 5.63$ & $133.68 \pm 4.47$ & $132.10 \pm 5.82$ & \multirow{3}{*}{$\begin{array}{c}0.129 \\
(2.066)\end{array}$} & \multirow{3}{*}{$\begin{array}{c}0.086 \\
(-0.122)\end{array}$} \\
\hline Min. - Max. & $120-145$ & $122-142$ & $116-148$ & & \\
\hline Median & 134 & 134 & 132 & & \\
\hline
\end{tabular}

Table 7: Relation between BMI and NSA.

\begin{tabular}{|c|c|c|c|c|c|c|}
\hline \multirow{2}{*}{$\begin{array}{c}\text { Angle } \\
(n=200)\end{array}$} & \multicolumn{4}{|c|}{ BMI } & \multirow{2}{*}{$\begin{array}{c}\text { p-value } \\
\text { (F) }\end{array}$} & \multirow{2}{*}{$\begin{array}{c}p \text {-value } \\
\text { (r) }\end{array}$} \\
\hline & $\begin{array}{c}<15 \\
(n=14)\end{array}$ & $\begin{array}{c}15-<20 \\
(n=124)\end{array}$ & $\begin{array}{l}20-<25 \\
(n=48)\end{array}$ & $\begin{array}{c}\geq 25 \\
(\mathrm{n}=14)\end{array}$ & & \\
\hline Mean \pm SD. & $136.93 \pm 5.25$ & $133.54 \pm 4.74$ & $132.75 \pm 5.51$ & $128.43 \pm 6.20$ & \multirow{3}{*}{$\begin{array}{l}\leq 0.001^{*} \\
(6.946)\end{array}$} & \multirow{3}{*}{$\begin{array}{l}\leq 0.001^{*} \\
(-0.270)\end{array}$} \\
\hline Min.-Max. & $130-145$ & $122-144$ & $120-148$ & $116-137$ & & \\
\hline Median & 134 & 134 & 132 & 128.5 & & \\
\hline
\end{tabular}

\section{Asymmetry and Femoral NSA}

Asymmetry in the human lower limb is frequently assumed to be low and random with respect to side, although some authors [11,40-42] have noted variably greater degrees of left leg robusticity in individual samples. If greater left leg robusticity is the dominant pattern, this should be reflected in lower neck shaft angles on the left side. Anderson and Trinkaus in their survey of femoral neck shaft angles in modern, historic, and prehistoric population samples reported that even though individual bilateral asymmetry existed in the NSA and some samples exhibited sexual dimorphism, there were no consistent patterns of asymmetry [43].

In the present study, there was no significant difference in the means of NSA of the right and left sides. However significant differences were found when right and left sides were compared in every subject (using Paired t-test) and we found that left side is equal to right side in 37 subjects, left is smaller than the right in 21 subjects with difference ranging from $1^{\circ}$ to $3^{\circ}$ and left is larger than the right in 42 subjects with difference ranging from $0.5^{\circ}$ to $4^{\circ}$. So, Asymmetry of the proximal femur especially NSA is assumed to be random with respect to side, showing a natural tendency to bilaterality.

\section{Age and Femoral NSA}

There are several factors quoted which influence NSA size in postnatal life: epiphyseal cartilage activity, perfusion of the femoral epiphysis, muscle action, hormones, static factors, body weight and, finally, disease. The most spectacular is the influence of age. During human growth from childhood to adulthood the CCD angle decreases significantly. This is a result of changes in body proportions followed by adaptation of the hip joint to vertical posture and gait in changed conditions $[44,45]$. The classical literature describes the angle of the femur axis or inclination angle as being of about $150^{\circ}$ in infants; $140^{\circ}$ in youngsters; $125^{\circ}$ in adults; and $120^{\circ}$ in the elderly [23].

Bulandra and his colleagues in their research performed on 106 human foetuses, 62 of which were male and 44 female in age from 16 to 38 weeks suggested that the process of adaptation to vertical posture and bipedal gait starts during pregnancy and is manifest as an inborn feature [1]. In the present study, we confirm the effect of age on the femoral NSA. As, we found a significant decrease in this angle with increase in age.

\section{Gender and Femoral NSA}

When searching for sexual differences in the NSA, some authors reported larger values of NSA in males than in females in adult age group $[16,30]$. In contrast, other authors documented no difference between both sexes [2,33]. In the current study, no significant sex-specific differences were found in the NSA.

\section{Biomechanical loading and Femoral NSA}

Since Humphry [8], it has been noted that there is a general inverse relationship between biomechanical loading levels at the hip and the NSA. The normal process of reduction in the angle to a 
more varus orientation of the femoral neck during development is dependent on the assumption of normal weight-bearing through the hip region and increasing locomotor activity levels during development [17,18, 21,46-48].

This is particularly evident in cases of reduced or absent weight-bearing during development. This is seen in infantile congenital dislocated hip [46-48], slipped femoral capital epiphysis [49], cerebral palsy [18,21] and immature idiopathic scoliosis [19]. In these cases of minimal weight-bearing, the femoral neck remains in a coxa valga position. Surgical correction of the condition with consequent normal weight-bearing produces 'a gradual decreasing of the NSA of the femur' over a period of a maximum of 2 years [48].

In addition, Houston and Zaleski demonstrated that, in immature individuals, the degree of decrease in femoral NSA during development is correlated with the level of normal physical activity. The higher the activity level, the greater the decrease in NSA from the neonatal value as the individual matures [17]. In the present study, we assessed the effect of body weight, height and BMI on the femoral NSA. We noticed that there was non-significant decrease in NSA with increase in height but, there was significant decrease in angle with increase in weight and BMI which may confirm the inverse relationship between biomechanical loading levels at the hip and the NSA. These considerations thus indicate that the femoral NSA is heavily influenced by load levels in the hip region during development. Eventually, further analyses and refinements in methodology used and population studied may be expected to clarify these findings and address some of the unresolved questions that surround the NSA, which may shed light on hitherto unexplored aspects of the proximal femoral geometry.

\section{Conclusion}

There are many factors which may influence NSA size, for example: studied population, age, weight, height, side, and BMI. Such findings may highlight the degree of variability likely to be encountered in this orthopaedically relevant region and challenge surgeons to be mindful of the impact that individual anatomic variation might have on outcomes for procedures not taking this variability into consideration.

\section{References}

1. Bulandra AM, Gielecki JS, Leciejewska I, Karaszewski P, Sieroń D (2003) Digital-image analysis of the femoral shaft/neck angle in human foetuses. Folia Morphol 62(4): 415- 417

2. Togwood PA, Skalak A, Cooperman DR (2009) Proximal Femoral Anatomy in the normal human population. Clin Orthop Relat Res 467(4): 876-885.

3. Ranawat AS, Kelly BT (2005) Anatomy of the Hip: Open and Arthroscopic Structure and Function. Opera Tech Orthop 15(3): 160174

4. Bonneau N, Libourel PA, Simonis C, Puymerial L, Baylac M, et al. (2012)
A three-dimensional axis for the study of femoral neck orientation. J Anat 221(5): 465- 476 .

5. Hefti F (2007) Pelvis, hips and thighs: Biomechanics of the hip. In: Pediatric Orthopaedics in Practice Springer-Verlag Berlin Heidelberg; New York, USA, pp. 169-176.

6. Schuenke M, Schutle E, Schumacher U (2006) Lower Limb: Bones, ligaments, and joints. In: Thieme Atlas of Anatomy: General Anatomy and Musculoskeletal System, $1^{\text {st }}$ edition, edited by Ross L and Lamperti E Georg Thieme Verlag, Stuttgart, New York, USA, pp. 360-418.

7. Charpy A (1885) Le col du fémur. Bulletin de la Société d' Anthropologie de Lyon 3: 282-300.

8. Humphry G (1889) The angle of the neck with the shaft of the femur at different periods of life and under different circumstances. J Anat Physiol 23: 273-282.

9. Bräuer G (1988) Osteometrie. In: Anthropologie I, edited by Krussmann R (Stuttgart: Fischer Verlag) 160-232.

10. Grine FE, Jungers WL, Tobias PV, Pearson OM (1995) Fossil Homo femur from Berg Aukas, northern Namibia. Am J Phys Anthropol 97(2):151-185.

11. Trinkaus E (1993) Femoral neck-shaft angles of the Qafzeh-Skuhl early modern humans, and activity levels among immature Near Eastern Middle Paleolithic hominids. J Hum Evol 25(5): 393-416.

12. Twiesselmann F (1961) Le fémur néanderthalian de Fond-de-Forêt (Province de Liège). Mémoire de l'Institut Royal des Sciences naturelles de Belgique 148: 1-164.

13. Clark JM, Freeman MAR, Witham D (1987) The relationship of neck orientation to the shape of the proximal femur. J Arthroplasty 2(2): 99-109.

14. Faulkner KG, Cummings S, Black D, PalermoL, Gluer C et al. (1993) Simple measurement of femoral geometry predicts hip fracture: the study of osteoporotic features. J Bone Min Res 8(10): 1211-1217.

15. Henriksson L (1980) Measurement of femoral neck anteversion and inclination. Acta Orthopaedica Scandinavica (Suppl.) 186: 1-59.

16. Hoaglund FT, Low WD (1980) Anatomy of the femoral neck and head, with comparative data from Caucasians and Hong Kong Chinese. Clin Orthop Relat Res 152: 10-16.

17. Houston CS, Zaleski WA (1967) The shape of vertebral bodies and femoral necks in relation to activity. Radiology 89(1): 59-66.

18. Laplaza FJ, Root L, Tassanawipas A, Glasser DB (1993) Femoral torsion and neck-shaft angles in cerebral palsy. J Pediatr Orthop 13(2): 192199.

19. Saji MJ, Upadhyay SS, Leong JCY (1995) Increased femoral neck-shaft angles in adolescent idiopathic scoliosis. Spine 20(3): 303-311.

20. Walensky NA, O'Brien MP (1968) Anatomical factors relative to the racial selectivity of general femoral neck fracture. Am J Phys Anthropol 28(1): 93-96.

21. Yamaguchi 0 (1993) A radiologic study of the hip joint in cerebral palsy. Journal of the Japanese Orthopaedic Association 67(1): 1-11.

22. Yoshioka Y, Siu D, Cooke TD (1987) The anatomy and functional axes of the femur. J Bone Joint Surg 69A(6): 873-880.

23. Isaac B, Vettivel S, Prasad R, Jeyaseelan L, Chandi G (1997) Prediction of the femoral neck-shaft angle from the length of the femoral neck. Clin Anat 10(5): 318-323.

24. Osorio H, Schorwer K, Coronado C, Delgado J, Aravena P (2012) Proximal femoral epiphysis anatomy in Chilean population. Orthopedic and forensic aspects. Int J Morphol 30(1): 258-262. 
25. Ravichandran D, Muthukumaravel N, Jaikumar R, Das H, Rajendran $M$ (2011) Proximal femoral geometry in Indians and its clinical applications. J Anat Soc India 60(1): 6-12.

26. Tahir A, Hassan AW, Umar IM (2001) A study of the collodiaphyseal angle of the femur in the North-Eastern Sub-Region of Nigeria. Niger J Med 10: 34-36.

27. Atilla B, Oznur A, Ocaglar O, Tokgozoglu M, Alpaslan M (2007) Osteotomy of the femora in Turkish individuals: a morphometric study in 114 cadaveric femora as an anatomic basis of femoral component design. Acta Orthop Traumatol Turc 41(1): 64-68.

28. De Sousa E, Fernandes RMP, Mathias MB, Rodrigues MR, Ambram AJ, et al. (2010) Morphometric study of the proximal femur extremity in Brazilians. Int J Morphol 28(3): 835-840.

29. Reikerås 0, Høiseth A, Reigstad A, Fonstelien E (1982) Femoral neck angles: a specimen study with special regard to bilateral differences. Acta Orthop Scand 53(5): 775-779.

30. Igbigbi PS, Msamati BC (2002) The femoral collodiaphyseal angle in Malawian adults. Am J Orthop 31(12): 682-685.

31. Igbigbi PS (2003) Collodiaphyseal angle of the femur in East African subjects. Clin Anat 16(5): 416-419.

32. Irdesel J, Ari I (2006) The proximal femoral morphometry of Turkish women on radiographs. Euro J Anat 10(1): 21-26.

33. Kaur P, Mathew S, George U (2013) A study of neck shaft angle in the North-West Indian population on radiographs. Int J Basic Appl Med Sc 3: 9-15.

34. Otsianyi WK, Naipanoi AP, Koech A (2011) The femoral collodiaphyseal angle amongst selected Kenyan ethnic groups. J Morphol Sci 28(2) 129-131.

35. Pulkkinen P, Partanen J, Jalovaara P, Jamsa T (2004) Combination of bone mineral density and upper femur geometry improves the prediction of hip fracture. Osteoporos Int 15(4): 274-280.

36. Saikia KC, Bhuyan SK, Rongphar R (2008) Anthropometric study of the hip joint in Northeastern region population with computed tomography scan. Indian J Orthop 42(3): 260-266.
37. Gnudi S, Ripamonti C, Gualtieri G, Malavolta N (1999) Geometry of proximal femur in the prediction of hip fracture in osteoporotic women. Brit J Radiol 72(680): 729-733.

38. Gnudi S, Ripamonti C, Lisi L, Fini M, Giardino R (2002) Proximal femur geometry to detect and distinguish femoral neck fractures from trochanteric fractures in postmenopausal women. Osteoporosis Int 13(1): 69-73.

39. Nissen N, Hauge EM, Abrahamsen B, Jensen JEB, Mosikilde L, et al. (2005) Geometry of the proximal femur in relation to age and sex: a cross-sectional study in healthy adult Danes. Acta Radiologica 46(5): 514-518.

40. Macho GA (1991) Anthropological evaluation of left-right differences in the femur of southern African populations. Anthropol Anz 49(3): 207-216.

41. Nwoha PU (1991) The collodiaphyseal angle of the femur in adult Nigerians. Afr J Med Med Sci 20(2): 143-147.

42. Ruff CB, Jones HH (1981) Bilateral asymmetry in cortical bone of the humerus and tibia - sex and age factors. Hum Biol 53(1): 69-86.

43. Anderson JY, Trinkaus E (1998) Patterns of sexual, bilateral and interpopulational variation in human femoral neck-shaft angles. J Anat 192(2): 279-285.

44. Dega W (1932) Badanie etiologii wrodzonego zwichnięcia biodra. Chir Narz Ruchu Ortop Pol 5: 161-296.

45. Moseley CF (1980) The biomechanics of the pediatric hip. Orthop Clin North Am 11(1): 3-16.

46. Houston CS (1978) The radiologist's opportunity to teach bone dynamics. J Can Assoc Radiol 29(4): 232-238.

47. Morscher E (1967) Development and clinical significance of the anteversion of the femoral neck. Reconstr Surg Traumatol 9: 107-125.

48. Serafimov L (1974) Biomechanical influence of the innominate osteotomy on the growth of the upper part of the femur. Clin Orthop Relat Res 98: 39-40.

49. Loder RT, Aronson D, Greenfield ML (1993) The epidemiology of

\section{Your next submission with Juniper Publishers will reach you the below assets}

- Quality Editorial service

- Swift Peer Review

- Reprints availability

- E-prints Service

- Manuscript Podcast for convenient understanding

- Global attainment for your research

- Manuscript accessibility in different formats

( Pdf, E-pub, Full Text, Audio)

- Unceasing customer service

Track the below URL for one-step submission https://juniperpublishers.com/online-submission.php 